light of an endothermic physiology reinterpreted. The text is well written, though the British publishers have apparently reprinted the American edition, as American spellings persist. The author has provided his own illustrations and succeeded remarkably in selling his argument by managing to give an intelligent and alert expression to the faces of the long-thought slothful dinosaurs. The arguments are put over clearly and persuasively, but the author too rarely considers alternative viewpoints to his own. I found his attitude to classical dinosaur reconstructions somewhat patronising, and felt that the criticisms of earlier workers were not entirely justified. Despite his biased view, the author has produced a book which is certainly stimulating, very readable and attractively presented, and which will appeal to anyone with an interest in dinosaurs, whatever their background.

John C.W. Cope

John C. W. Cope is Senior Lecturer in Geology at University College, Swansea, UK.

\section{In the hands of the rockhounds}

MINERALOGY is increasingly in the hands of the rockhounds. Short courses in gemology and the lapidary arts are oversubscribed and will hopefully lead on to a much wider public interest in the earth sciences in general. Sadly, one consequence is that well-known mineral localities, and some which once were near-secret, are picked over and almost barren. Disused workings are being closed for safety reasons and recent legislation all but bans collectors from active mines. For all except the mundane, many collectors are forced to buy imported specimens and professional collecting has become highly profitable. It is not unknown for bona fide scientific collectors or the casual amateur to be literally driven off outcrops by well equipped and frenzied dealers or their suppliers. In this context, the publication of three new books aimed at the amateur can be received with some misgivings. Not one of them pays any attention to the pressure on sites nor to conservation practices. That being said, professional geologists should attempt to encourage wider interest and activity in this field as a route to popularising earth sciences. But to what extent do the new books contribute to this aim?

The Hamlyn Nature Guide to Minerals by Andrew Clark (Hamlyn: London and New York; $£ 1.95$ ) is a thin book, in all respects. it claims to be a practical identification guide but its brief introduction to mineral properties is too dry for the beginner. Its 436 colour photographs are pretty enough, but the brief mineral descriptions are not arranged in a suitable format for easy identification. The order is the conventional composition/atomic structure classification, which is no guide to minerals' immediate appearance. No information about localities is given but there are very brief notes on geological setting, which will certainly not aid the non-geologist to find good specimens. Perhaps this is a book for the pure conservationist.

The Audubon Society Field Guide to North American Rocks and Minerals by Charles W. Chesterman (Knopf; New York; \$9.95) is in another class. It contains 794 magnificent colour photographs and is virtually a self-contained introduction to geology through its more aesthetic products. The book begins with a simple but comprehensive account of the diagostic properties of minerals. The ordering of photographs does not match that in the identification tables or the extended mineral by mineral descriptions - the photographs being arranged by colour and form, the tables by colour and hardness. But this is only a minor irritation, albeit unecessary. The quality of specimens was a little daunting for this casual collector and perhaps for even more determined rockhounds. This reflects the use of tiny specimens or micromounts - forced on

\section{How to grow your own rubies}

IF you want an excuse not to give your wife an opal for Christmas, you will find one in D. Elwell's book: Man-Made Gemstones (Ellis: Chichester, UK; Wiley \& Halstead: New York; £15), both natural and synthetic opals are porous, and serious cracking can occur if they are immersed in warm soapy water.

Far better to give her a ruby "Growing rubies by the flame fusion process in the garage is possible, but not recommended. We will therefore consider flux growth" . . . Dr Elwell goes on to give detailed instructions, but briefly you take a platinum crucible, mix lead fluoride with the oxides of lead, boron, aluminium and chromium, add a pinch of lanthanum oxide to improve crystal shape, put in the oven at $250^{\circ} \mathrm{C}$ for 24 hours, allow to cool slowly, and extract your crystals using nitric acid.

Unfortunately, your home-grown rubies, though real, will be "synthetic". This is an important qualification. modern collectors by the self-induced dearth of 'mantle piece' specimens. Common rocks are well treated and sufficient space has been devoted to introducing the elements of the science, as well as the hobby, to make this book a notable contribution in the field and excellent value.

Rock and Mineral Collecting in Britain by Peter R. Rodgers (Faber and Faber: London, hardback £6.95, paperback $£ 3.50$ ) is a good text for absolute beginners and relates mineral occurrences to geological setting quite adequately. However, the simplification into igneous, sedimentary and metamorphic classes of deposits can be misleading at this elementary level, and arguably a better approach would have been regional descriptions of famous mineral sites. The localities listed seems impressive, but the reader soon finds those mentioned in the text very elusive. The most useful items are the mineral catalogue and the list of localities with grid references. There are glaring omissions among the localities and the list would have been better organised region by region with accompanying maps. Several famous British minerals, noteably mimetite, harmotome, torbanite and alstonite are in-explicably absent. The beginner will find this an encouraging little volume, but a little extra documentation might have found a ready demand among more experienced collectors.

Stephen A. Drury

Stephen A. Drury is Lecturer in the Department of Earth Sciences at the Open University, Milton Keynes, UK.

Synthetic gemstones are identical, chemically and crystallographically speaking, to the real thing; but they are usually distinguishable from, and therefore less valuable than, natural gemstones. 'Imitation' or 'simulated' gems on the other hand resemble the real thing but are actually a different material; thus yttrium aluminium garnet (YAG) and cubic zirconia are both used as diamond simulants.

Opals do have their own fascination, as Elwell explains, even if you cannot yet grow your own. They are unique among gemstones in being an ordered array of silica crystallites, whose spacing leads to diffraction of visible light and hence to a captivating play of colours as the gem is moved. Most other gemstones are genuine crystals - an ordered array of atoms and are transparent, whereas opal is opaque.

I certainly enjoyed reading Dr Elwell's book. Although ruby is the only crystal he gives a recipe for, he also describes the synthesis of sapphire, spinel, emerald, diamond and its simulants, and many other precious and semiprecious stones.

Gemology (Wiley-Interscience: New York and Chichester, UK; $£ 13.50$ ) by the 